\title{
Metabolic Syndrome and Bone Mineral Density in Post Menopausal Women: Is There Any Link?
}

\author{
Abourazzak $\mathrm{F}^{1 *}$, Essouiri J ${ }^{1}$, Lazrak $\mathrm{F}^{1}$, Azzouzi $\mathrm{H}^{1}$, Keita $\mathrm{S}^{2}$, Ragragui $\mathbf{S}^{1}$, Rhazi $\mathrm{K}^{2}$, \\ Errasfa $\mathbf{M}^{3}$, Harzy $\mathbf{T}^{\mathbf{1}}$ \\ ${ }^{1}$ Rheumatology Department, Hassan II University Hospital, Fez, Morocco. \\ ${ }^{2}$ Laboratory of Epidemiology and Public Health, Faculty of Medicine and Pharmacy, Sidi Mohamed Ben Abdellah University, Fez, Morocco. \\ ${ }^{3}$ Pharmacology Department, Faculty of Medicine and Pharmacy, Sidi Mohamed Ben Abdellah University, Fez, Morocco.
}

Received: October 02, 2016; Accepted: November 10, 2016; Published: November 15, 2016

*Corresponding author: Fatima Ezzahra Abourazzak, Rheumatology Department, Hassan II University Hospital, Fez, Morocco, Phone: 002126 616018 14; Fax: 002125356127 94; E-mail: f.abourazzak@yahoo.fr

\begin{abstract}
Introduction: Metabolic Syndrome (MetS) may have a protective or a negative effect on bone. The predominance of different components in individual patients may contribute to inconsistent results regarding its relationship with bone mineral density. Thus we analyzed the link between MetS and each of its components, and Bone Mineral Density (BMD) in post menopausal women.
\end{abstract}

Methods: We conducted a cross sectional study including post menopausal women with and without MetS according to the National Cholesterol Education Program Adult Treatment Panel III criteria. The two groups were compared for BMD after adjusting for covariates that affected BMD significantly. A stepwise multiple linear regression analysis was used to identify independent predictors of BMD.

Results: We included 170 women, 81 with MetS and 89 without MetS. The prevalence of MetS was $48 \%$. In women with MetS, the mean BMD was $0.915 \pm 0.159 \mathrm{~g} / \mathrm{cm}^{2}$ in lumbar spine and $0.865 \pm 0.143$ $\mathrm{g} / \mathrm{cm}^{2}$ in total hip. No significant statistical difference was found in comparison with the MetS free group $\left(0.928 \pm 0.160 \mathrm{~g} / \mathrm{cm}^{2} ; \mathrm{p}=0.61\right.$ in lumbar spine, and $0.845 \pm 0.143 \mathrm{~g} / \mathrm{cm}^{2} ; \mathrm{p}=0.29$ in total hip). Multiple regression analyses showed that waist circumference was associated with bone loss in lumbar spine $(p=0,003)$, while triglycerides was non-associated with bone loss on total hip ( $\mathrm{p}=0.05)$.

Conclusion: It seems that BMD is not associated to MetS in post menopausal women. Abdominal obesity might be associated with bone loss underlying the possible effect of inflammation in pathophysiology of osteoporosis and bone loss.

Keywords: Bone mineral density; Metabolic Syndrome; Post menopausal Women;

\section{Abbreviations}

MetS: Metabolic syndrome; BMD: Bone Mineral Density; OP: Osteoporosis; BMI: Body Mass Index; BP: Blood Pressure; NCEP/ATP III: National Cholesterol Education Program Adult Treatment Panel III; HDL: High Density Lipoprotein; LDL: Low Density Lipoprotein; TG: Triglycerides; SD: Standard Deviation.

\section{Background}

Metabolic syndrome (MetS) is a heterogeneous and multi factorial human disorder associated with increased cardiovascular risk [1]. It is a very common medical problem and its prevalence is rapidly increasing in industrialized countries.

Osteoporosis (OP) is a skeletal disorder characterized by compromised bone strength that predisposes affected persons to an increased risk of fracture and consequently to high morbidity and mortality [2]. In our context, $46 \%$ of post menopausal women develop at least one vertebral fracture [3].

Although the relationship between cardiovascular disease and osteoporosis has been widely studied, the association between metabolic syndrome, a strong risk factor for vascular disease, and bone loss has not been extensively addressed, and studies are controversial. A study conducted in the USA has found, after adjusting for age, gender, and other covariates, that femur neck BMD was higher in subjects with MetS [4]. In the Camargo Cohort Study, women with MetS had higher age-adjusted BMD at the total hip, femur neck, and lumbar spine than MetS-free women [5]. On the other hand, men with MetS had a lower BMD at the femur neck in the Rancho Bernardo Study after adjusting for Body Mass Index (BMI) [6]. In addition, a recent Korean study has reported that women with MetS also have a lower BMD at the lumbar spine [7].

The joint occurrence of the two diseases is thought to result from the common risk factors and path physiological mechanisms, such as smoking, a sedentary lifestyle, sex hormone deficiency, low-grade inflammation, and increased oxidative stress [8-11]. Cumulative evidence has demonstrated that increased bone loss and a lower bone mass are associated with cardiovascular mortality $[12,13]$ and that an increased risk of cardiovascular events is proportional to osteoporosis severity at the time of diagnosis [14]. MetS is characterized by a proinflammatory state that negatively affects cardiovascular risk [15], and OP is linked to inflammation $[16,17]$. Proinflammatory cytokines up-regulate 
receptor activators of nuclear factor Kappa B ligand, leading to increased bone resorption and osteoporosis [18-20]. In addition, because metabolic syndrome consists of several single components that could have their own independent relationship with osteoporosis, the possible association of each of them with the skeletal disease is also worth considering [21-25].

The aim of this study was to evaluate the effect of MetS on BMD in post menopausal women, and to assess the relationship between each component of MetS and BMD.

\section{Materials and methods}

\section{Study design and participants}

We conducted a cross sectional study. The study population consisted of consecutive post Menopausal women who had undergone a medical visit in the rheumatology department of Hassan II University Hospital. Postmenopausal status was defined as cessation of menses for at least 1 year. Each subject was asked to complete a questionnaire to determine age, age at menarche, age at menopause, history of previous medical or surgical disease, personal and familial history of osteoporotic fracture, medication history, tobacco and alcohol use, and physical exercise (More or less than three times per week).

All subjects underwent a medical interview and a thorough medical examination. The height and weight of each patient were obtained with them wearing indoor clothing and without shoes. Body Mass Index (BMI) was then calculated as weight $(\mathrm{kg})$ divided by square of height (m). Waist circumference (in centimeter) was measured on bare skin between the tenth rib and the iliac crest at the end of a normal expiration. Blood Pressure (BP, in millimeter of mercury), with systolic and diastolic measures, using a calibrated aneroid sphygmomanometer was recorded twice after resting for more than $15 \mathrm{~min}$. The average of two measurements was used.

Exclusion criteria were: (1) personal history of early menopause ( $<40$ years), (2) missing information about menopausal history or if the subject had undergone a hysterectomy prior to natural menopause, (3) nulliparity, (4) use of alcohol, (5) use of drug that can affect bone metabolism such as hormone therapy, anticonvulsivants or corticosteroids, (6) taking medication for osteoporosis, diabetes hypertension or hypercholesterolemia, (7) malignancy, (8) thyroid disease or thyroid function abnormality, (9) inactive life style with limited physical activity (paraplegia, stroke, dementia...), and (10) acute infection or chronic inflammatory disease.

The study was approved by the local ethics committee of the Faculty of Medicine; Sidi Mohammed Ben Abdellah University. All women gave written informed consent.

\section{Metabolic syndrome}

Metabolic syndrome was defined according to the National Cholesterol Education Program Adult Treatment Panel III (NCEP/ATP III) criteria [26]. Women were classified as having MetS when any three or more of the following items were present: abdominal obesity (waist circumference $\geq 80 \mathrm{~cm}$ ); serum triglyceride levels $\geq 150 \mathrm{mg} / \mathrm{dL}(1.7 \mathrm{mmol} / \mathrm{L})$ or High Density Lipoprotein (HDL) cholesterol levels $<50 \mathrm{mg} / \mathrm{dL}(1.3 \mathrm{mmol} / \mathrm{L})$; blood pressure $\geq 130 / 85 \mathrm{~mm} \mathrm{Hg}$; and fasting glucose level $\geq$ $100 \mathrm{mg} / \mathrm{dL}$ (5.6mmol/L). Receiving specific treatment for one criterion is counted as fulfilling the criterion.

\section{BMD measurements}

The BMD was measured by dual energy X-ray absorptiometry using a Lunar Prodigy (GE Medical, Madison, WI, USA), calibrated daily using a standard phantom provided by the manufacturer. BMD was measured at the lumbar spine and total hip, and was expressed in absolute values $\left(\mathrm{g} / \mathrm{cm}^{2}\right)$.

\section{Statistical analysis}

The statistical analysis was performed with SPSS Version 18.0. All data are presented as the mean \pm Standard Deviation (SD) for quantitative variables, and as percentages for qualitative variables. Demographic characteristics of subjects with and without MetS were compared using Student's $t$-test or MannWhitney $U$ test for continuous variables, and the chi-square test for categorical variables.

Analysis of Covariance (ANCOVA) was used to compare the BMD levels of women with and without MetS after adjusting for significant BMD covariates including age, BMI, and physical exercise.

A stepwise multiple linear regression analysis was used to identify independent predictors of BMD of the lumbar spine and total hip.

The Statistical significance was set as $\mathrm{p} \leq 0.05$.

\section{Results}

The study included 170 women. The mean age was $58.98 \pm$ 6.58 [44-78] years, and the mean BMI was $29.72 \pm 4.09$ [18.4$42.7] \mathrm{kg} / \mathrm{m}^{2}$. According to NCEP/ATP III definition, the prevalence of metabolic syndrome was $48 \%$. Table 1 shows the clinical characteristics and laboratory parameters of the participants studied according to the presence or absence of MetS. Women with MetS were older with higher BMI. They also had greater values of wait circumference, fasting glucose, triglycerides, and systolic blood pressure, and lower serum HDL cholesterol concentration. No significant difference was found in either serum $25(\mathrm{OH})$ vitamin D or total alkaline phosphatase levels in women with and without MetS.

We performed correlation analyses between lumbar spine and total hip BMD, and the known BMD covariates (Table 2). Age showed a negative correlation, and weights a positive correlation with BMD in both sites. Height and BMI had a positive correlation with respectively lumbar spine and total hip BMD.

We analyzed BMD values in lumbar spine and total hip in women with and without MetS (Table 3). It does not seem that BMD is associated to MetS. These findings remained unchanged after adjusting for age, BMI and exercise.

To identify the independent factors affecting the BMD of 
Table 1: Baseline characteristics and laboratory data.

\begin{tabular}{|c|c|c|c|}
\hline & $\begin{array}{l}\text { Women with MetS } \\
(\mathrm{n}=\mathbf{8 1})\end{array}$ & $\begin{array}{l}\text { Women without MetS } \\
(\mathrm{n}=89)\end{array}$ & $\mathbf{p}$ \\
\hline Age (years) & $60 \pm 7.64$ & $58 \pm 6.88$ & 0.05 \\
\hline Age of menopause (years) & $49.11 \pm 7.48$ & $48.92 \pm 5.3$ & 0.84 \\
\hline Smokers (n, \%) & 0 & 0 & - \\
\hline Drinkers (n, \%) & 0 & 0 & - \\
\hline Height (cm) & $159.7 \pm 5.03$ & $159.7 \pm 4.9$ & 0.980 \\
\hline Weight (kg) & $78.6 \pm 10.20$ & $73.04 \pm 10.54$ & $<0.001$ \\
\hline BMI $\left(\mathrm{Kg} / \mathbf{m}^{2}\right)$ & $30.73 \pm 4$ & $23.80 \pm 3.98$ & 0.002 \\
\hline Exercise (>3/week) (n, \%) & $47(49.5)$ & $48(50.5)$ & 0.351 \\
\hline \multicolumn{4}{|l|}{ MetS components } \\
\hline Waist circumference $(\mathrm{cm})$ & $93.78 \pm 7$ & $88.79 \pm 8.6$ & $<0.001$ \\
\hline Fasting glucose $(\mathrm{mg} / \mathrm{dL})$ & $120.54 \pm 37$ & $98 \pm 14.5$ & $<0.001$ \\
\hline Triglycerides $(\mathrm{mg} / \mathrm{dL})$ & $165 \pm 62.39$ & $121.69 \pm 37.39$ & $<0.001$ \\
\hline$H D L c(m g / d L)$ & $45 \pm 10.16$ & $59.32 \pm 11$ & $<0.001$ \\
\hline Systolic BP $(\mathrm{mm} \mathrm{Hg})$ & $13.12 \pm 1.3$ & $12.66 \pm 0.74$ & 0.004 \\
\hline Diastolic BP $(\mathrm{mmHg})$ & $8 \pm 1$ & $7.82 \pm 0.61$ & 0.21 \\
\hline Calcium (mg/dL) & $9.65 \pm 1.06$ & $9.3 \pm 0.45$ & 0.005 \\
\hline Phosphate (mg/dL) & $3.55 \pm 0.9$ & $3.57 \pm 0.9$ & 0.72 \\
\hline Alkaline phosphatase (UI/L) & $137.10 \pm 37$ & $128.37 \pm 56$ & 0.455 \\
\hline $25(\mathrm{OH})$ vitamin $\mathrm{D}(\mathrm{ng} / \mathrm{mL})$ & $17.6 \pm 11.9$ & $18.34 \pm 9.69$ & 0.378 \\
\hline LDLc (mg/dL) & $119 \pm 40$ & $124 \pm 31$ & 0.31 \\
\hline \multicolumn{4}{|c|}{ Prevalence of the MetS components } \\
\hline Abdominal obesity ( $n, \%)$ & $77(58)$ & $56(42.1)$ & $<0.001$ \\
\hline Hyperglycemia $(n, \%)$ & $45(81.8)$ & $10(18.2)$ & $<0.001$ \\
\hline Hypertriglyceridemia $(n, \%)$ & $49(76.6)$ & $15(23.4)$ & $<0.001$ \\
\hline Low $\operatorname{HDLc}(n, \%)$ & $68(86.1)$ & $11(14)$ & $<0.001$ \\
\hline $\operatorname{High} B P(n, \%)$ & $43(84.3)$ & $8(15.7)$ & $<0.001$ \\
\hline
\end{tabular}

Table 2: Correlation between BMD and clinical parameters.

\begin{tabular}{|l|c|c|}
\hline & \multicolumn{2}{|c|}{ Pearson correlation } \\
\hline Age (y) & Lumbar spine & Total hip \\
\hline $\begin{array}{l}\text { Age of menopause } \\
\text { (y) }\end{array}$ & $-0.250^{*}$ & $-0.248^{*}$ \\
\hline Height $(\mathbf{c m})$ & -0.125 & -0.065 \\
\hline Weight $(\mathbf{k g})$ & $0.158^{*}$ & 0.060 \\
\hline BMI $\left(\mathbf{k g} / \mathbf{m}^{2}\right)$ & $0.189^{*}$ & $0.221^{*}$ \\
\hline Exercise & 0.121 & $0.212^{*}$ \\
\hline$* \mathrm{p}<0.05$ & -0.13 & 0.04 \\
\hline
\end{tabular}

lumbar spine and total hip according to the metabolic states, we performed a stepwise multiple linear regression analysis, having BMD as a dependent variable and MetS parameters, age, BMI and exercise as independent variables (Table 4). Significant predictive factors for the BMD were age and exercise in the lumbar spine, and age and BMI in the total hip.
Multiple regression analyses were performed to examine the effect of each component of MetS on BMD in lumbar spine and total hip after adjusting for confounding variables (Table 5). In lumbar spine, waist circumference had a negative effect on BMD after adjusting for covariates, while triglycerides had a positive effect on BMD in the base, but this finding disappeared after adjusting for covariates. In total hip, only triglycerides had a positive effect on BMD. This effect remained unchanged after adjusting for all covariates.

Linear regression analyses between $25(\mathrm{OH})$ vitamin D, total alkaline phosphatase, and the five single components of MetS were performed. No significant association was found between each of the five MetS components and the two biologic parameters.

\section{Discussion}

In this study, we did not found any difference in lumbar and total hip BMD in post menopausal women according to the presence or absence of MetS. The literature data about this association is inconclusive. Higher [4-6] and lower [7, 27- 
Table 3: BMD findings by Metabolic Syndrome status.

\begin{tabular}{|c|c|c|c|}
\hline & $\begin{array}{c}\text { Presence of } \\
\text { MetS } \\
(\mathbf{n = 8 1})\end{array}$ & $\begin{array}{c}\text { Absence of } \\
\text { MetS } \\
\text { (n=89) }\end{array}$ & $\mathbf{p}$ \\
\hline Lumbar spine & & & \\
\hline Unadjusted & $0.915 \pm 0.159$ & $0.928 \pm 0.160$ & 0.61 \\
\hline Age adjusted & $0.916 \pm 0.135$ & $0.934 \pm 0.150$ & 0.44 \\
\hline Age + BMI & $0.911 \pm 0.153$ & $0.939 \pm 0.160$ & 0.24 \\
\hline All covariates & $0.912 \pm 0.153$ & $0.938 \pm 0.150$ & 0.29 \\
\hline Total hip & & & \\
\hline Unadjusted & $0.865 \pm 0.143$ & $0.845 \pm 0.143$ & 0.29 \\
\hline Age adjusted & $0.867 \pm 0.135$ & $0.836 \pm 0.141$ & 0.42 \\
\hline Age + BMI & $0.860 \pm 0.135$ & $0.843 \pm 0.141$ & 0.41 \\
\hline All covariates & $0.861 \pm$ & 0.842 & \\
\hline
\end{tabular}

All covariates: Age +BMI+ Exercise

Table 4: Stepwise multiple linear regression analysis with bone mineral density as a dependent variable, and metabolic syndrome parameters, age, BMI and exercise as independent variables.

\begin{tabular}{|l|c|c|}
\hline & $\boldsymbol{\beta}$ & $\mathbf{p}$ \\
\hline Lumbar spine & & \\
\hline Age & -0.006 & $\mathbf{0 . 0 0 1}$ \\
\hline BMI & 0.005 & 0.09 \\
\hline Exercise & -0.067 & $\mathbf{0 . 0 0 5}$ \\
\hline Total hip & & \\
\hline Age & -0.005 & $\mathbf{0 . 0 0 1}$ \\
\hline BMI & 0.007 & $\mathbf{0 . 0 0 7}$ \\
\hline Exercise & -0.014 & 0.50 \\
\hline
\end{tabular}

30] BMD values have been reported for women with MetS compared with women without MetS. Yoldemir et al reported that the mean $\mathrm{T}$ scores for the lumbar area for women with or without MetS were comparable either according to NCEP/ ATP III criteria [31], which agrees with our results. These controversial findings may be explained by the fact that MetS is composed from several components, and each one could have a negative or a protective effect on BMD. The concept of MetS is not meaningful in the context of bone mineral density, and the analysis of BMD variation according to the global criterion MetS may obscure pathophysiologic links of BMD with its individual components. Thus, the discordant results of the studies analyzing the association between MetS and BMD may reflect the heterogeneous character of MetS and partly depend on the different rates of prevalence of individual components of MetS in various cohorts. Some of MetS components have been studied such as obesity and diabetes. Despite the high risk of fracture in type 2 diabetic women, hyperinsulinemia accompanied by MetS increases Bone Mineral Density (BMD) [21]. Concerning abdominal obesity, the balance between the possible protection afforded by increased body weight and the damage caused by the inflammatory state has led to controversial results in clinical studies assessing Bone Mineral Density (BMD) [22-25].

We performed a multiple regression analyses to examine the effect of each component of MetS on BMD in both sites after adjusting for confounding variables. When we considered each component of MetS as an independent variable, a higher waist circumference was most significantly associated with lower BMD at lumbar spine. This means that subjects with abdominal obesity are more likely to have lower BMD at lumbar spine. No difference related to abdominal obesity was found at total hip. The reason for the difference between the two sites is not definite, but as shown in the stepwise multiple regression analyses, it appears that the stronger positive correlation between BMI and BMD at the total hip ( $\beta=0.007 ; p=0.007)$ could have a greater effect on the association between waist circumference and BMD at the total hip. Indeed, general obesity and body weight are the strongest protectors against bone loss by exercising greater load on the lower limbs and trunk [32]. Other mechanisms related to obesity may also explain its protective effect such as higher $17 \beta$-estradiol [33-35] and insulin [36] levels, and some adipokines especially lower adiponectin and higher leptin [37-39]. Also, it seems that visceral obesity is influencing mainly trabecular bone [40]. The negative association between waist circumference and BMD has been reported in the literature which is in total accord with our findings $[29,41]$. Visceral fat is not only specialized with regard to the storage and mobilization of lipids but also a remarkable endocrine organ that release proinflammatory cytokines stimulating bone resorption such as TNF alpha, interleukin 6 , and Interleukin 18 [42-44]. Therefore, it is feasible that the resultant low-grade inflammation, which is known to be involved in the pathophysiologic mechanisms underlying osteoporosis [10], may lead to bone loss despite the protective effects of general obesity. In other studies, abdominal obesity was found to be a protective factor on BMD at the lumbar spine [5], the total hip [5, 27], and the femoral neck [5]. Currently, the mechanism of the effect of fat on bone is not clear. A number of mechanisms for the fat-bone relationship exist and include the effect of soft tissue mass on skeletal loading, the association of fat mass with the secretion of bone active hormones from the pancreatic beta cell (including insulin, amylin, and preptin), and the secretion of bone active hormones (e.g., estrogens and leptin) from the adipocyte. These factors alone probably do not fully explain the observed clinical associations, and study of the actions on bone of novel factors is an important area of further research.

In our study, triglycerides level correlated positively with total hip BMD. Similar data was reported in literature. Indeed, higher triglycerides level was associated with a less bone loss $[6,27,45]$, and with a lower risk of vertebral and non-vertebral fractures [41, 46-48]. This relationship was significant when adjusted for BMD confounders. Thus its mechanism remains unclear. Experimental data suggest that apolar lipids, including TG, form a layer between collagen fibers and mineral crystals [49]. Triglycerides may mediate the interaction between protein matrix and bone mineral and contribute to the improvement of qualitative properties of bone [41]. 
Table 5: Multiple regression analysis to determine the independent effects of each specific component for metabolic syndrome on bone mineral density.

\begin{tabular}{|c|c|c|c|c|c|c|c|c|}
\hline & \multicolumn{2}{|c|}{ Unadjusted } & \multicolumn{2}{|c|}{ Age adjusted } & \multicolumn{2}{|c|}{ Age + BMI } & \multicolumn{2}{|c|}{ All covariates } \\
\hline & $\mathbf{r}$ & $\mathbf{p}$ & $\mathbf{r}$ & $\mathbf{p}$ & $\mathbf{r}$ & $\mathbf{p}$ & $\mathbf{r}$ & $\mathbf{p}$ \\
\hline \multicolumn{9}{|l|}{ Lumbar spine } \\
\hline Waist circumference & -0.013 & 0.740 & -0.043 & 0.137 & -0.004 & 0.05 & -0.005 & 0.003 \\
\hline Fasting glucose & 0.026 & 0.443 & 0.010 & 0.686 & 0.004 & 0.869 & 0.001 & 0.3 \\
\hline Triglycerides & 0.070 & 0.05 & 0.008 & 0.757 & -0.001 & 0.978 & 0.001 & 0.16 \\
\hline HDL cholesterol & -0.020 & 0.607 & -0.023 & 0.340 & -0.033 & 0.176 & 0.001 & 0.29 \\
\hline Systolic BP & -0.003 & 0.921 & 0.013 & 0.245 & 0.011 & 0.316 & 0.009 & 0.43 \\
\hline \multicolumn{9}{|l|}{ Total hip } \\
\hline Waist circumference & -0.024 & 0.504 & 0.003 & 0.911 & -0.029 & 0.300 & -0.002 & 0.152 \\
\hline Fasting glucose & 0.027 & 0.377 & 0.024 & 0.295 & 0.014 & 0.536 & 0.001 & 0.70 \\
\hline HDL cholesterol & 0.017 & 0.629 & 0.005 & 0.815 & -0.009 & 0.663 & 0.001 & 0.11 \\
\hline Systolic BP & -0.008 & 0.757 & 0.011 & 0.292 & 0.008 & 0.447 & 0.008 & 0.45 \\
\hline
\end{tabular}

All covariates: Age $+\mathrm{BMI}+$ Exercise

Data on the link between other components of MetS Blood pressure and serum concentrations of glucose and HDL cholesterol- and BMD are conflicting. Similarly to our data, BMD was not associated with fasting glucose [5, 27-30], with HDLc [5, $7,27,29]$, and with systolic blood pressure [27-29].

Several potential limitations should be considered in the interpretation of our data. First, our recruitment was based on patients who underwent a clinical examination in our university hospital. These subjects may not be representative of the general population. Second, this was a cross sectional study, limiting our ability to determine the cause and effect of MetS and each of its components with the respect to BMD. We could assess only the temporal relationship. Further prospective studies should be performed to determine a causal relationship between these variables. Finally, prevalent fractures and the risk of fractures were not measured in our study. Although MetS do not affect BMD quantitatively, the bone quality could be deteriorated.

\section{Conclusion}

In summary, our findings reveal that even if the presence of MetS as a global entity has no impact on BMD in post menopausal women, the association between individual component of MetS and low BMD is not excluded. That is because of the characteristics of MetS including both obesity and inflammation. Indeed, abdominal obesity in post menopausal women is the most important factor associated with bone loss, especially in lumbar spine. These results underline the role of inflammation in the pathophysiology of osteoporosis and bone loss.

\section{Acknowledgment}

\section{Authors' contributions}

FA and FL have drafted the manuscript.

FA, FL, HA, JE, and SR have made substantial contributions to conception and design, acquisition and interpretation of data.

TH and ME supervised the study's design and planning, and revised the final manuscript.

SK and KR performed the statistical analysis.

All authors read and approved the final manuscript.

\section{References}

1. Miranda PJ, DeFronzo RA, Califf RM, Guyton JR. Metabolic syndrome: definition, pathophysiology, and mechanisms. Am Heart J. 2005;149(1):33-45. DOI:10.1016/j.ahj.2004.07.013.

2. NIH Consensus Development Panel on Osteoporosis Prevention, Diagnosis, and Therapy: Osteoporosis prevention, diagnosis, and therapy. JAMA. 2001;285:785-795.

3. Rostom S, Allali F, Bennani L, Abouqal R, Hajjaj-Hassouni N. The prevalence of vertebral fractures and health-related quality of life in postmenopausal women. Rheumatol Int. 2012;32(4):971-980. doi: 10.1007/s00296-010-1734-5.

4. Kinjo M, Setoguchi S, Solomon DH. Bone mineral density in adults with the metabolic syndrome: analysis in a population based U.S. sample. J Clin Endocrinol Metab. 2007;92:4161-4164. doi: 10.1210/jc.20070757.

5. Hernandez JL, Olmos JM, Pariente E, Martinez J, Valero C, GarciaVelasco P, et al. Metabolic syndrome and bone metabolism: the Camargo Cohort study. Menopause. 2010;17:955-961. doi: 10.1097/ gme.0b013e3181e39a15.

6. von Muhlen D, Safii S, Jassal SK, Svartberg J, Barrett-Connor E. Associations between the metabolic syndrome and bone health in older men and women: the Rancho Bernardo Study. Osteoporos Int. 2007;18:1337-1344.

7. Hwang DK, Choi HJ. The relationship between low bone mass and metabolic syndrome in Korean women. Osteoporos Int. 2010;21:425431. doi: 10.1007/s00198-009-0990-2.

8. Szulc P, Garnero P, Claustrat B, Marchand F, Duboeuf F, Delmas PD. Increased bone resorption in moderate smokers with low body 
weight: the Minos study. J Clin Endocrinol Metab. 2002;87:666-674. DOI: $10.1210 /$ jcem.87.2.8232.

9. Fink HA, Ewing SK, Ensrud KE, Barrett-Connor E, Taylor BC, Cauley $\mathrm{JA}$, et al. Association of testosterone and estradiol deficiency with osteoporosis and rapid bone loss in older men. J Clin Endocrinol Metab. 2006;91:3908-3915.

10. Koh JM, Khang YH, Jung CH, Bae S, Kim DJ, Chung YE, et al. Higher circulating hsCRP levels are associated with lower bone minera density in healthy pre- and postmenopausal women: evidence for a link between systemic inflammation and osteoporosis. Osteoporos Int. 2005;16:1263-1271. DOI:10.1007/s00198-005-1840-5.

11. Almeida M, Han L, Martin-Millan M, Plotkin LI, Stewart SA, Roberson $\mathrm{PK}$, et al. Skeletal involution by age-associated oxidative stress and its acceleration by loss of sex steroids. J Biol Chem. 2007;282:2728527297. DOI: $10.1074 /$ jbc.M702810200.

12. Kado DM, Browner WS, Blackwell T, Gore R, Cummings SR. Rate of bone loss is associated with mortality in older women: a prospective study. J Bone Miner Res. 2000;15:1974-1980. DOI: 10.1359/ jbmr.2000.15.10.1974.

13. von der Recke P, Hansen MA, Hassager C. The association between low bone mass at the menopause and cardiovascular mortality. Am J Med. 1999;106:273-278.

14. Tanko LB, Christiansen C, Cox DA, Geiger MJ, McNabb MA, Cummings SR. Relationship between osteoporosis and cardiovascular disease in postmenopausal women. J Bone Miner Res. 2005;20:1912-1920.

15. Lee WY, Park JS, Noh SY, Rhee EJ, Sung KC, Kim BS, et al. C-reactive protein concentrations are related to insulin resistance and metabolic syndrome as defined by the ATP III report. Int J Cardiol. 2004;97:101106. DOI:10.1016/j.ijcard.2003.08.016.

16. Ganesan K, Teklehaimanot S, Tran TH, Asuncion M, Norris K. Relationship of C-reactive protein and bone mineral density in community-dwelling elderly females. J Natl Med Assoc. 2005;97:329333.

17. Koh JM, Khang YH, Jung CH, Bae S, Kim DJ, Chung YE, et al. Higher circulating hsCRP levels are associated with lower bone minera density in healthy pre- and postmenopausal women: Evidence for a link between systemic inflammation and osteoporosis. Osteoporos Int. 2005;16:1263-1271. DOI:10.1007/s00198-005-1840-5.

18. Jones DH, Kong YY, Penninger JM: Role of RANKL and RANK in bone loss and arthritis. Ann Rheum Dis. 2002;61 Suppl 2: ii32-39.

19. Hofbauer LC, Schoppet M. Clinical implications of the osteoprotegerin/ RANKL/RANK system for bone and vascular diseases. JAMA. 2004:292 490-495. DOI:10.1001/jama.292.4.490.

20. Smith BJ, Lerner MR, Bu SY, Lucas EA, Hanas JS, Lightfoot SA, et al. Systemic bone loss and induction of coronary vessel disease in a rat model of chronic inflammation. Bone. 2006;38(3): 378-386. DOI:10.1016/j.bone.2005.09.008.

21. Barrett-Connor E, Kritz-Silverstein D. Does hyperinsulinemia preserve bone? Diabetes Care. 1996;19:1388-1392.

22. Ravn P, Cizza G, Bjarnason NH, Thompson D, Daley M, Wasnich RD, et al. Low body mass index is an important risk factor for low bone mass and increased bone loss in early postmenopausal women. Early Postmenopausal Intervention Cohort (EPIC) study group. J Bone Miner Res. 1999;14:1622-1627. DOI:10.1359/jbmr.1999.14.9.1622.

23. Smith BJ, Lerner MR, Bu SY, Lucas EA, Hanas JS, Lightfoot SA, et al. Systemic bone loss and induction of coronary vessel disease in a rat model of chronic inflammation. Bone, 2006:38(3):378-386 DOI:10.1016/j.bone.2005.09.008.

24. Kim BJ, Yu YM, Kim EN, Chung YE, Koh JM, Kim GS. Relationship between serum hsCRP concentration and biochemical bone turnover markers in healthy pre- and postmenopausal women. Clin Endocrinol (Oxf). 2007;67(1):152-158. DOI:10.1111/j.1365-2265.2007.02853.x.

25. Xue P, Gao P, Li Y. The association between metabolic syndrome and bone mineral density: a meta-analysis. Endocrine. 2012;42(3):546554. doi: $10.1007 /$ s12020-012-9684-1.

26. Grundy SM, Cleeman JI, Daniels SR, Donato KA, Eckel RH, Franklin BA, et al. American Heart Association; National Heart, Lung, and Blood Institute. Diagnosis and management of the metabolic syndrome: an American Heart Association/National Heart, Lung, and Blood Institute Scientific Statement. Circulation. 2005;112(7):2735-2752. DOI:10.1161/CIRCULATIONAHA.105.169404.

27. Kim BJ, Ahn SH, Bae SJ, Kim EH, Kim TH, Lee SH, et al. Association between metabolic syndrome and bone loss at various skeletal sites in postmenopausal women: a 3-year retrospective longitudinal study. Osteoporos Int. 2013;24:2243-2252. doi: 10.1007/s00198-0132292-y.

28. Park KK, Kim SJ, Moon ES. Association between bone mineral density and metabolic syndrome in postmenopausal Korean women. Gynecol Obstet Invest 2010,69:145-152. doi: 10.1159/000264665.

29. Kim HY, Choe JW, Kim HK, Bae SJ, Kim BJ, Lee SH, et al. Negative association between metabolic syndrome and bone mineral density in Koreans, Especially in men. Calcif Tissue Int. 2010;86(5):350-358. doi: 10.1007/s00223-010-9347-2.

30. Jeon YK, Lee JG, Kim SS, Kim BH, Kim SJ, Kim YK, et al. Association between bone mineral density and metabolic syndrome in pre- and postmenopausal women. Endocrine Journal 2011;58(2):87-93.

31. Yoldemir T, Erenus M. The impact of metabolic syndrome on bone mineral density in post menopausal women. Gynecological Endocrinology. 2012;28:391-395.

32. Ahmed LA, Schirmer H, Berntsen GK, Fønnebø V, Joakimsen RM. Features of the metabolic syndrome and the risk of non vertebral fractures: the Tromso study. Osteoporos Int. 2006;17(3):426-432. DOI:10.1007/s00198-005-0003-z.

33. Nelson LR, Bulun SE. Estrogen production and action. J Am Acad Dermatol. 2001;45(3):S116-S124.

34. Szulc P, Munoz F, Claustrat B, Garnero P, Marchand F, Duboeuf F, et al. Bioavailable estradiol may be an important determinant of osteoporosis in men: the MINOS study. J Clin Endocrinol Metab. 2001;86(1):192-199. DOI:10.1210/jcem.86.1.7126.

35. Ohta H, Ikeda T, Masuzawa T, Makita K, Suda Y, Nozawa S. Differences in axial bone mineral density, serum levels of sex steroids, and bone metabolism between postmenopausal and age- and body sizematched premenopausal subjects. Bone. 1993;14(2):111-116.

36. Stolk RP, Van Daele PL, PolsHA, Burger H, HofmanA, Birkenhager $\mathrm{JC}$, et al. Hyperinsulinemia and bone mineral density in an elderly population: the Rotterdam Study. Bone. 1996;18(6):545-549.

37. Reid I, Richards JB. Adipokine effects on bone. Clin Rev Bone Miner Metab. 2009;7(3):240-248.

38. Biver E, Salliot C, Combescure C, Gossec L, Hardouin P, Legroux-Gerot I, et al. Influence of adipokines and ghrelin on bone mineral density and fracture risk: a systematic review and meta-analysis. J Clin Endocrinol Metab. 2011;96(9):2703-2713. doi: 10.1210/jc.2011-0047. 
39. de Albuquerque Maia L, Lisboa PC, de Oliveira E, da Silva Lima N, Lima IC, Lopes RT, et al. Bone metabolism in obese rats programmed by early weaning. Metabolism. 2014;63(3):352-364. doi: 10.1016/j. metabol.2013.11.010.

40. Jankowska EA, Rogucka E, Medras M. Are general obesity and visceral adiposity in men linked to reduced bone mineral content resulting from normal ageing? A population based study. Andrologia. 2001;33(6):384-389.

41.Szulc P, Varennes A, Delmas PD, Goudable J, Chapurlat R. Men with metabolic syndrome have lower bone mineral density but lower fracture risk-the MINOS study. J Bone Miner Res. 2010;25(6):14461454. doi: 10.1002/jbmr.13.

42. Kern PA, Ranganathan S, Li C, Wood L, Ranganathan G. Adipose tissue tumor necrosis factor and interleukin-6 expression in human obesity and insulin resistance. Am J Physiol Endocrinol Metab. 2001;280:E745-E751.

43. Berg AH, Scherer PE. Adipose tissue, inflammation, and cardiovascular disease. Circ Res. 2005;96(6):939-949.

44. Hung J, McQuillan BM, Chapman CML, Thompson PL, Beilby JP Elevated inteleukin-18 levels are associated with the metabolic syndrome independent of obesity and insulin resistance. Arterioscler Thromb Vasc Biol. 2005;25:1268-1273.

45. Edelstein SL, Barrett-Connor E. Relation between body size and bone mineral density in elderly men and women. Am J Epidemiol. 1993;138(3):160-169.

46. Muhlen D, van Saffi, Jassal SK, Svartberg J, Barrett-Connor E. Associations between the metabolic syndrome and bone health in older men and women: the Rancho Bernardo study. Osteoporos Int. 2007;18(10):1337-1344. DOI:10.1007/s00198-007-0385-1.

47. Yamaguchi T, Kanazawa I, Yamamoto M, Kurioka S, Yamauchi M, Yano $\mathrm{S}$, et al. Associations between components of the metabolic syndrome versus bone mineral density and vertebral fractures in patients with type 2 diabetes. Bone. 2009;45(2):174-179. doi: 10.1016/j. bone.2009.05.003.

48. Sivas F, Alemdarog lu E, Elverici E, Kulug T, Ozoran K. Serum lipid profile: its relationship with osteoporotic vertebrae fractures and bone mineral density in Turkish postmenopausal women. Rheumatol Int. 2008;29(8):885-890. doi: 10.1007/s00296-008-0784-4.

49. Xu S, Yu JJ. Beneath the minerals, a layer of round lipid particles was identified to mediate collagen calcification in compact bone formation. Biophys J. 2006;91(11):4221-4229. DOI:10.1529/ biophysj.105.075804. 